\title{
Genetics loads the gun, lifestyle pulls the trigger
}

\section{Opinion}

I just finished watching a presentation by Barbara O'Neill called The True Cause of Diseases. Pretty amazing presentation but one of her statements, amongst many, really grabbed my attention: "Genetics Loads the Gun, Lifestyle Pulls the Trigger". What a profound statement, just THINK about it's implications!

Most people think that Lifestyle means the lives of the rich and famous and never think about how they live their lives. That is lifestyle, how you choose to live your life on a daily basis. What you do, what you eat, how you interact with others; that is Lifestyle. It is the force, an energy that defines all living things, that surrounds and penetrates living beings and is structured by the genetic code and fueled/directed by what you eat. Lifestyle is focused by how you act, how you interact with your environment and how active you are.

Lifestyle is a choice you see. How you use your life force on a daily basis, how you fuel your body and how you structure your activities that constitute your life. Living is nothing but a series of choices, good ones and not so good ones. When we are younger, the impact of many lifestyle choices don't have an immediate impact but they can build up, like waters behind a dam that can crack or break, causing a flood of disease that results from the lifestyle you have chosen to live!

The genetics you were born with are pretty much fixed but do not necessarily control how you will live. Like a light switch, genes are either on or off. Information Technology folks can relate to this binary control mechanism better than others. Think of the millions upon millions of genes in your genetic structure as gates, open or closed, that direct your life force one direction or another. Your lifestyle and diet control many of these gates and can open or close them guiding your body's mechanisms toward health or disease.

The gates are controlled by you and your lifestyle. You control your life. Learning how diet and nutrition contribute to the gene gates can be instrumental on how you plan and live your life. How you choose to consume food that provides the energy and building blocks that fuel your body.

Your body is an absolutely amazing creation supported by eons of evolution that created the being that is you. You are unique, no other person has ever possessed the exact genetic structure that is you, and never will. That makes you not only unique but extraordinarily complex.

Science is just beginning to understand just how complex we are. Many scientists believe they know how this complexity of human beings and the life force works but they are totally deluding themselves and the rest of the community of human beings. In order to convince the general populace that they actually understand and know something, they use the power of fear to intimidate.

Most modern day medicine is based on fear. Fear of disease, fear of aging, fear of dying. Nothing but fear to intimidate and much like those genetic gates, drive you towards a lifestyle that generates huge profits to the medical communities, pharmaceuticals and commercial agribusiness that control the fuel you use to power your life force.

\author{
Volume 3 Issue 2 - 2015
}

\author{
Skip Stein \\ Plant Based Lifestyle Consultant, Whole Foods 4 Healthy Living, \\ USA
}

Correspondence: Skip Stein, Plant Based Lifestyle Consultant, Chief Operating Officer,Whole Foods 4 Healthy Living, Orlando, Florida, Tel 4076836816,

Email skipstein@wholefoods4healthyliving.com

Received: December 5, 2015 | Published: December 19, 2015

What if they are wrong? What if you have been directed by intimidation and fear to ignore the truth that they really don't know what they are doing? The truth never contradicts itself, yet there are contradictory 'facts' promulgated by medical and nutritional resources constantly. Once cigarettes were considered healthy! Now genetically modified food is considered healthy.

Antibiotics are wonders of modern medicine but like those gates, they direct you towards dependency and their overuse have polluted the landscape. Drugs with often deadly/debilitating effects are pushed with fear by marketing agencies focused on generating massive profits for the pharmaceutical companies. Doctors are effectively bribed with 'benefits' by salespeople who push the profitable drugs to be prescribed by physicians instead of searching for the truth and cause of the disease.

What if there is another, simpler way, supported by the truth of the ages and history of mankind. The truth that the living force that powers the human body (and all life on our Planet) is self sustaining and a balanced existence that is regenerative and self healing? What if your lifestyle not only might contribute to disease but the selection of alternative lifestyle that controls the genetic gates can reverse or cure disease?

Einstein defined insanity as doing the same thing over and over and expecting different results. Has humanity become insane? We are dosing the population with drugs, supported by fear mongering that obfuscates the truth that there are alternatives that work just as well if not better. We are expecting the failed medical establishment to repeat the same never ending treatments, that never actually cure much, over and over yet expecting a different result? What has so called, modern medicine cured lately? They treat people to death but seldom actually permanently cure much of anything.

Less complex ways to support your life force, strengthen your body's health are readily and inexpensively available today, now, immediately. Yes, it can be difficult at first but almost immediately rewarding and self-reinforcing. That is a change in lifestyle, a change in how you live, what you eat and how you interact with the forces that surround us all. Often the simplest solutions are the most obscure/ hidden by those whose vested interest conflict with the simplest and most natural and proven solutions. 
That simple solution, one that is inexpensive and readily available, if you seek it out, is that a Plant-Based Lifestyle can help open the good genetic gates and keep the bad ones closed. A more natural, selfhealing lifestyle, with a reduced dependency on drugs is available to you today, now, immediately.

Remember that the truth never contradicts itself and the truth is that reinforcing the body's natural life force and self healing immune system may be the most effective way to limit disease and promote a vibrant healthy lifestyle for the rest of your long life. Remember, Genetics loads the gun, but lifestyle pulls the trigger. Make sure that when you pull the trigger the target is a healthy plant-based lifestyle that closes the gates to disease and opens the ones to a long and vibrant life!

\section{Acknowledgements}

None.

\section{Conflict of interest}

Author declares that there is no conflict of interest. 